\title{
Las batallas de Kuruyuki. Variaciones sobre una derrota chiriguana
}

Les batailles de Kuruyuki. Variations sur une défaite chiriguana

The Battles of Kuruyuki. Variations on a Chiriguano defeat

\section{Isabelle Combès}

\section{(2) OpenEdition}

Journals

Edición electrónica

URL: https://journals.openedition.org/bifea/5493

DOI: $10.4000 /$ bifea.5493

ISSN: 2076-5827

Editor

Institut Français d'Études Andines

Edición impresa

Fecha de publicación: 1 agosto 2005

Paginación: 221-233

ISSN: 0303-7495

Referencia electrónica

Isabelle Combès, «Las batallas de Kuruyukt. Variaciones sobre una derrota chiriguana», Bulletin de I'Institut français d'études andines [En línea], 34 (2) | 2005, Publicado el 08 août 2005, consultado el 28 juin 2022. URL: http://journals.openedition.org/bifea/5493 ; DOI: https://doi.org/10.4000/bifea.5493

\section{(@) $\Theta \Theta \Theta$}

Les contenus du Bulletin de l'Institut français d'études andines sont mis à disposition selon les termes de la licence Creative Commons Attribution - Pas d'Utilisation Commerciale - Pas de Modification 4.0 International. 


\title{
Las batallas de Kuruyuki. Variaciones sobre una derrota chiriguana
}

\author{
Isabelle Combès*
}

\section{Resumen}

Kuruyuki es la última batalla que enfrentó, en 1892, a una parte de los chiriguanos del Chaco boliviano con los blancos. Marcó, para la gente de la época, el fin de esta etnia. Después de un largo silencio sobre el tema, tanto de parte de los historiadores como de los mismos chiriguanos, los estudios se multiplican a partir de 1972, y con ellos las diferentes explicaciones, justificaciones y recuperaciones del acontecimiento. Ocaso, suicidio o resurrección, unión sagrada o resultado de discordias internas: la historia de Kuruyuki es, en gran medida, la historia de sus historias. Se analizan aquí estas diferentes historias, en función de quién escribe o habla, cuándo, y movido por cuáles intereses inmediatos. Teorías antropológicas, movimientos indígenas y regionalismos son algunos de los factores que contribuyen a moldearlas.

Palabras clave - chiriguanos, Chaco, manipulación histórica, etnohistoria, movimientos indígenas

\section{Les batailles de Kuruyuki. Variations sur une défaite chiriguana}

\section{Résumé}

Kuruyuki est la dernière bataille qui a opposé, en 1892, une partie des Chiriguanos du Chaco bolivien contre les blancs. Elle marqua, pour les gens de l'époque, la fin de cette ethnie. Après un long silence sur ce thème, de la part des historiens comme des Chiriguanos eux-mêmes, les études se multiplient à partir de 1972, et avec elles les différentes explications, justifications et récupérations de l'événement. Crépuscule, suicide ou résurrection, union sacrée ou résultat de dissensions internes : l'histoire de

* Investigadora del Instituto Francés de Estudios Andinos. Correo electrónico: kunhati@gmail.com Este artículo fue presentado en el 2004 Annual Meeting of the American Society of Ethnohistory, Chicago, 29 de octubre de 2004. Agradezco a Catherine Julien por su invitación a Chicago; a Diego Villar y Kathleen Lowrey por sus comentarios a una primera versión de este ensayo; a Thomas Abercrombie y Vincent Hirtzel por la evaluación que hicieron del mismo. 
Kuruyuki est, dans une large mesure, I'histoire de ses histoires. On analyse ici ces différentes histoires, en fonction de qui écrit ou parle, quand, et mû par quels intérêts immédiats. Théories anthropologiques, mouvements indiens et régionalismes sont quelques-uns des facteurs qui contribuent à les dessiner.

Mots clés - Chiriguanos, Chaco, manipulation historique, ethnohistoire, mouvements indiens

\title{
The Battles of Kuruyuki. Variations on a Chiriguano defeat
}

\begin{abstract}
The battle of Kuruyuki, in 1892, was the last time in which part of the Chiriguano of the Bolivian Chaco fought against the Whites. Several opinions have stated that this battle meant the end of this ethnic group. However, after a long silence both by the historians and the Chiriguano themselves, since 1972 a vast number of studies, explanations and justifications of Kuruyuki have been finally published. Successively interpreted as decline, suicide or resurrection, as a sacred union or as a consequence of internal discord, the history of Kuruyuki is therefore a history of its histories. The different versions of it are analyzed in this article, bearing in mind who wrote them and when they were written, as well as the motives and interests of the authors. Anthropological theories, indigenous movements and regionalisms -among other significant factors- have influenced the succesive authors.
\end{abstract}

Key-Words - Chiriguano, Chaco, historical manipulation, ethnohistory, indigenous movements

Nunca podremos comprender el «hecho» que sucedió «realmente» [...] El punto de vista sobre el pasado, la manipulación de la memoria por todos aquellos que se consagran sucesivamente a narrar el pasado, nunca es inocente.

(Duby, 1988: 77-78)

La batalla de Kuruyuki, que enfrentó por última vez a chiriguanos y blancos en el Chaco boliviano, tuvo lugar el 28 de enero de 1892. Fue para los chiriguanos un fracaso total, que dejó un saldo de miles de muertos; fue, también, la última vez que la etnia tomó las armas contra los blancos.

Poco después de la batalla, un contemporáneo dio su veredicto:

«La tribu de los chiriguanos, altanera y soberbia, no se resigna fácilmente a ser dominada [...] Sucumbió sin rendirse». (Nino, 1918: 246)

Ochenta años después de la revuelta, un historiador concluye: los chiriguanos, «como nación, habían terminado para siempre» (Sanabria, 1972: 217); más tarde, otro evoca la «extinción» de la etnia «como sociedad independiente» en 1892 (Saignes, 1990: 9). Y apenas dos años después de tan pesimista veredicto, un siglo después de la batalla misma, un joven chiriguano proclama, en las trincheras de Kuruyukt: «Este pueblo estaba muerto y ha resucitado» (in Pifarré, 1992: 10).

Dos discursos —o más - sobre un mismo acontecimiento; dos visiones —o más— de la historia: ¿dos errores, dos mentiras? Es evidente que no son las palabras adecuadas. Un error 
supone una equivocación involuntaria, «inocente»; una mentira supone por el contrario una voluntad afirmada de ocultar ciertas cosas, o de hacer creer otras... y debemos recordar que «del puro y simple engaño hasta el error enteramente involuntario, hay muchos matices» (Bloch, 2002 [1949]: 100).

De estos matices, precisamente, quisiera hablar en estas líneas. Hablar de Kuruyuki, sí, pero sobre todo de los Kuruyuki: de sus diferentes interpretaciones o recuperaciones, de sus diferentes historias. Quiero considerar los discursos que existen sobre «el hecho de Kuruyuki» (discursos que varían según las épocas, es decir según la historia) como hechos que también son y hacen historia, y que por tanto deben estudiarse como tales. Más que de la historia de los indios, quiero hablar aquí de los historiadores de los indios y, last but not least, de «los indios como historiadores» (Nordenskiöld, 2002 [1912]: 155). Y si alguna «mentira» se cruza en nuestro camino, pues, pensemos que «después de todo [...], no es sino la verdad bajo una máscara», como decía Lord Byron.

\section{EL CONTEXTO}

Los chiriguanos (hoy llamados y autodenominados «guaraní») son uno de los grupos étnicos más numerosos del Chaco boliviano, y uno de los más estudiados de un punto de vista histórico. $\mathrm{El}$ «origen» mismo de la etnia puede ser leído en las fuentes coloniales tempranas, que evocan el mestizaje biológico y cultural entre migrantes guaraní llegados de Brasil y Paraguay en los siglos XV y XVI, y grupos autóctonos chané, de filiación arawak (Combès \& Saignes, 1991). Dominando sobre el plano político a los chané o tapii («esclavos»), «guaranizándoles» cultural y lingüísticamente, los chiriguanos se constituyeron en los siglos coloniales como el principal obstáculo de los españoles de Charcas para penetrar en el Chaco. Con una fama comparable a la de los araucanos de Chile, opusieron una tenaz resistencia a la penetración española hasta fines del siglo XVIII, o incluso fines del siglo XIX, según las regiones. Acabaron, sin embargo, vencidos paulatinamente por la clásica trilogía colonizadora española y republicana: la misión, el ejército y la hacienda.

La resistencia chiriguana al español se inició a pequeña escala, con combates aislados de algunas «capitanías», «parcialidades» o zonas. A partir del siglo XVIII se hacen más frecuentes las «coaliciones» o «sublevaciones generales» que reúnen a varias capitanías contra un enemigo común: la sublevación de 1727 al mando de Aruma, la de 1750 encabezada por Chindica, la poderosa coalición de los años 1793 a 1799 que acabó destruyendo a muchas misiones franciscanas, la sublevación general de 1849 o la de 1874. Entre estos movimientos, los de 1778 merecen una mención especial por el carácter mesiánico que tuvieron. Tanto en Caiza al sur como en Mazavi en el corazón de la «Chiriguanía», las rebeliones fueron dirigidas por los llamados tumpa («dios»), al parecer herederos de los profetas y chamanes tupí-guaraní de Paraguay y Brasil1. La última sublevación chiriguana, en 1892, también fue encabezada por un joven tumpa.

La rebelión empieza en el año 1889, cuando el tumpa inicia sus primeras apariciones públicas, incitando a la guerra en contra de los karai. A finales del año 1891, en Ivo y Cuevo, se agudizan los problemas; a pesar de la intervención conciliadora de los padres franciscanos de Cuevo, un incidente es el detonante de la guerra: en la noche del $1^{\text {ro }}$ de enero de 1892, el corregidor karai (blanco) de Cuevo, ebrio, viola y mata a una mujer chiriguana pariente de un mburuvicha (jefe, «capitán») local (Sanabria, 1972; Chavarría, 1892).

1 Sobre los movimientos proféticos tupí-guaraní, ver por ejemplo Métraux (1967), Susnik (1968) y Clastres (1975). EI movimiento de Mazavi en 1778 tuvo probablemente una influencia directa del Paraguay. Si las fuentes franciscanas (AFT M224; ANB EC 1782/9) solo hablan del «dios fingido» de Mazavi y sus acompañantes, las autoridades de la época dicen que el tumpa es «un mestizo Paraguayo» (ANB Rück 56; ANB EC 1795/52). 
Durante todo el mes de enero la cordillera chiriguana se enciende, con ataques esporádicos a puestos ganaderos e incluso un intento — fracasado - de toma de la misión de Santa Rosa de Cuevo. Varias capitanías chiriguanas están unidas en la lucha y bajo las órdenes del tumpa; otras se mantienen neutrales, o incluso apoyan a la represión del movimiento. La reacción del ejército boliviano no se hace esperar. Las primeras tropas llegan a Ivo y Cuevo desde los pueblos de los alrededores inmediatos, como Gutiérrez, Charagua, Lagunillas, Sauces y Muyupampa. Cerca de Ivo, en la comunidad de Kuruyukí, los chiriguanos sublevados se atrincheran. Llegan a finales de enero tropas militares desde Santa Cruz de la Sierra, y son ellas que libraron la batalla final, después de la cual arriba recién a la zona, desde Sucre, el coronel Melchor Chavarría (Sanabria, 1972; Chavarría, 1892; Martarelli, 1892).

La historia de Kuruyuki termina así el 28 de enero de 1892, con la muerte de casi un millar de chiriguanos a manos del ejército boliviano. Muchos logran huir, entre ellos el tumpa, traicionado más tarde por uno de sus propios compañeros. El 29 de marzo es el doloroso epílogo, con la ejecución en Sauces (hoy Monteagudo) del que se conoce hoy como Apiaguaiqui, o Apiaiqui, o Hapia oeki Tumpa2. De diciembre de 1891 hasta marzo de 1892, entre las diversas escaramuzas, el asalto a la misión de Santa Rosa, la batalla de Kuruyuki y la persecución de fugitivos, más de 6000 chiriguanos perecieron (Chavarría, 1892: 30)3.

\section{KURUYUKł: ¿EPÍLOGO O SUICIDIO FRACASADO?}

El 28 de enero de 1892 fue un fracaso para los chiriguanos, una masacre, una carnicería: esto nadie lo duda. Y si bien hubo tímidos intentos de sublevaciones en los meses y años posteriores (ver por ejemplo Nordenskiöld, 2002 [1912]: 122; Combès, 1991; periódico La Estrella del Oriente de los 4, 18 y 25 de mayo de 1892), Kuruyuki fue la última batalla verdadera, la última lucha, armas en mano, contra los karai o blancos. Marcó el fin de un largo período iniciado en 1559 con las incursiones de Andrés Manso en el país chiriguano y los primeros brotes de una tenaz resistencia por parte de las diferentes «capitanías» o zonas chiriguanas. Tan tenaz que los chiriguanos fueron uno de los pocos pueblos amerindios a quienes el rey de España declaró oficialmente la guerra a finales del siglo XVI, a través del virrey Toledo; tan tenaz que los chiriguanos guardan hasta hoy una evidente fama de guerreros simbolizada hoy, en la ciudad de Santa Cruz de la Sierra, por la estatua solitaria y altiva de un kereimba (guerrero).

El fracaso de Kuruyuki marcó así, tanto para los padres franciscanos (Martarelli, testigo de la batalla, y Nino) como para los historiadores, el fin de una etnia definida ante todo por su capacidad de resistencia y de lucha. Lorenzo Calzavarini habla del «ocaso» de un pueblo que fue «grande»; Kuruyuki «[...] fue la conclusión de cinco siglos de lucha [...] llegó a su ocaso la 'nación' chiriguana» (Calzavarini, 1980: 280, 294). Sanabria Fernández hace del tumpa el

2 Sanabria Fernández (1972) se anotició del nombre de Apiaguaiqui por Santos Aireyu en Kaipependi. Antes de él, el único que mencionó el nombre del tumpa (Apiawaiki) fue, en 1929, Alfred Métraux (1967). Este nombre fue interpretado luego por Francisco Pifarré (1989: 375) como Hapia oeki Tumpa: «Dios le sacó los testículos, eunuco de Dios». Esta versión se enfrenta con dos problemas: primero, las pocas fuentes contemporáneas que dan el nombre del tumpa lo llaman Apiaiqui (Chavarría, 1892, 4) o Apiaíque (Anales del Colegio Franciscano de Tarija, 1892, 110-111-AFT H1); segundo, según el antropólogo y lingüista Bret Gustafson, así como se habla en guaraní de Aguara Tumpa: Zorro-Dios, Hapia oeki Tumpa podría significar "Castrado-Dios", pero en ningún caso «castrado por Dios». Gustafson (com. pers.) propone, al revés, algo como Japia ko, o Japiavai ko, es decir, «que tiene testículos», «muy macho», versión que me parece más probable no sólo lingüística sino culturalmente hablando. La misma interpretación fue sugerida por Saignes (1990: 190).

3 Las cifras de Chavarría son aproximadas y existen errores en las sumas del número de muertos, heridos y prisioneros. Sanabria Fernández (1972: 229-230) reproduce las cifras de Chavarría, pero cambiando varias cifras de manera totalmente arbitraria. 
«último caudillo» de los chiriguanos. Otro historiador escribe: «[...] la noche se iba a apoderar del pueblo chiriguano» (Pifarré, 1989: 387). Saignes no duda en emplear palabras tan fuertes como «aniquilamiento» o «agonía» (Saignes, 1985: 176).

Si todos coinciden sobre el «fin» de los chiriguanos en 1892, los historiadores difieren sobre el sentido y el por qué de este fin. Todos, sin embargo, se basan sobre lo que Branislava Susnik (1968) definió como la característica de los chiriguanos y como su ideal étnico: el concepto de iyambae, el proclamarse hombres «sin dueño». Los cronistas franciscanos del siglo XIX expresan a su manera este ideal chiriguano: «son celosísimos de su autonomía e independencia» (Giannecchini, 1996 [1898]: 161); chiriguano es sinónimo de «no esclavo» para Comajuncosa:

«Significamos con este nombre unas gentes [...] repugnantes a todo lo que es sujeción, servicio, pagamentos de tributos y otras pensiones». (Comajuncosa \& Corrado, 1884: 136)

Sanabria Fernández, Calzavarini o Pifarré presentan la batalla de Kuruyuki como el último sobresalto desesperado de todo un pueblo unido contra su opresor. «La Chiriguanía no aguanta más a cristianos ni a civilizados... [es un] choque secular entre los dos modos de ser sociedad», escribe Lorenzo Calzavarini (1980: 231). Kuruyuki llegó a ser la masacre que fue porque los chiriguanos prefirieron la muerte a la esclavitud.

«Jamás se resignan a servir de esclavos a los cristianos; prefieren más bien morir [o] emigrar a otras partes [...] El chiriguano por su natural independiente aborrece la sujeción y la esclavitud más que la muerte». (Martarelli, 1918 [1889]: 173, 301)

«Morir antes que esclavos vivir»... el refrán del himno nacional boliviano es primero, en esta perspectiva, un lema chiriguano. Y después del fracaso de 1892, desaparece la etnia: porque está muerta, porque está esclava, porque migró, porque se mestizó. Es en referencia al mestizaje con los blancos que Sanabria Fernández escribió en 1973 que «quien quiera hoy hallar chiriguanos en Cordillera y el Chaco, tendrá que buscar mucho, y no siempre con fortuna» (nota a Moreno, 1973: 547); es también en referencia a la esclavitud de los peones chiriguanos en las haciendas criollas que Nino notó:

«El chiriguano de hoy no es el de otros tiempos [...] Hoy el temido chiriguano se halla humillado é inclina su frente altanera; se ha reducido a la nada». (Nino, 1912: 115, 273)

En sus escritos tempranos, Saignes enfatiza que los chiriguanos

«[...] han cesado de vivir en tanto que indios. Excluidos de sí mismos, refugiados de ninguna parte, esperan la formalidad biológica, ya que su corazón fue enterrado en 1892». (Saignes, 1974: 412)

Más tarde sin embargo, el mismo Saignes propondrá importantes matices a esta tesis. Si no emplea prácticamente nunca la palabra iyambae ${ }^{4}$, utiliza el concepto del «hombre sin dueño» en una interpretación resueltamente «clastreana» de la historia chiriguana. El ideal de independencia o de no sumisión de los chiriguanos es, más que la no sumisión a los blancos, el ideal de la «sociedad contra el Estado» (Clastres, 1974): el ideal de una sociedad que rechaza un poder coercitivo interno, la sumisión a un jefe separado del grupo, a un Estado incipiente. El «ser chiriguano», dice en sustancia Saignes, es — para emplear las expresiones de Clastres (1980) _ un «ser-para-la-guerra», en tanto que «ser-contra-el-Estado».

Basándose en una sólida documentación histórica, Saignes hace de las eternas disensiones entre «capitanías» o «provincias» chiriguanas y de la guerra intratribal la esencia misma de la sociedad chiriguana (Saignes, 1982; 1985; 1990: cap. I). La guerra chiriguana, dice Saignes, tiene la

4 Sólo encontré una mención concreta de la palabra en el diálogo que siguió una ponencia de Thierry Saignes, donde el historiador francés se refiere, siguiendo a Susnik (1968), al «ideal tribal de "hombre sin dueño"». (Saignes, 1986: 189) 
misma función que las migraciones y el profetismo guaraní tales como los analizó Hélène Clastres (1975): una función «centrífuga», un mecanismo de defensa contra la acción «centrípeta» de un incipiente poder separado de la sociedad, de un Estado. Las rivalidades incesantes entre capitanías y jefes chiriguanos, las luchas que ocasionan, no permiten el surgimiento de una cabeza única y unificadora de un pueblo o una «nación» (en el sentido político del término):

«Se dio a las "guerras chiriguanas" el color de una lucha colectiva contra el invasor blanco y mestizo sin ver que primaban rivalidades internas a las cuales estaba subordinada la lucha anti-colonial. No se entendió que la cohesión del conjunto étnico se fundamenta en la oposición de sus comunidades locales, esto es entre partes de sí-mismo. Cuesta captar una identidad colectiva que se reproduce mediante un desgarramiento interno perpetuo que plantea a la vez fragmentación territorial y cohesión local, alianzas y enfrentamientos aleatorios. Por eso la proyección de un concepto occidental como el de "nación" mistifica más que ayuda a entender la especificidad de la forma social ava»5. (Saignes, 1990: 11-12)

Este proceso mismo, por su exacerbación, desembocó en el fracaso de Kuruyuki y el «fin» de la etnia: de la misma manera que, según la interpretación de Hélène Clastres (1975), el profetismo guaraní de Paraguay, «contra el Estado» al igual que las guerras chiriguanas, apuntaba a la autodestrucción de la sociedad.

Que Kuruyuki haya fracasado por culpa de las disensiones internas entre diferentes grupos chiriguanos, también fue notado por otros autores, como Erick Langer (1994). Sanabria Fernández, quien presenta el retrato de un solo pueblo unido contra los blancos, menciona, sin embargo, también estas disensiones: de los seis «grandes capitanes» de la época, uno solo apoyó decididamente al tumpa: el jefe Güiracota. Otros, como Tengua, tuvieron una actitud muy ambigua; otros, como Mandepora en Macharetí, guardaron una «neutralidad» peligrosa para el éxito del movimiento. Otros, como Chituri en el Gran Parapiti, apoyaron a los blancos. Los neófitos de las misiones franciscanas, los chiriguanos peones del Ingre y otros de la zona del Isoso marcharon también, a veces obligados, a veces no, en contra del tumpa. En el mismo orden de cosas, Sanabria menciona la deserción del capitán Anduari de Ivo, quien buscó refugio en la misión de Santa Rosa (Sanabria, 1972: 155). Los chiriguanos de las misiones no solo permanecieron fieles a los sacerdotes, sino que Mandepora, de Macharetí, parece haber dado el aviso del próximo ataque de la misión de Santa Rosa (Nino, 1912: 167, 275). Los Anales del colegio franciscano de Tarija subrayan que

«[...] en el alzamiento de los Chiriguanos no tomaron parte ni nuestros Misioneros [indios de las misiones], ni los Tobas aliados ni otras tribus del oriente; y esto se debió y se debe al calumniado y perseguido Mandeponai, Capitán de Macharetí, injustamente acusado como cómplice de la sublevación». (AFT H1, reproducido in Giannecchini, 1996 [1898]: 262)

Más aún, Martarelli indica que la tropa que dio el asalto final a Kuruyuki en enero de 1892 estaba compuesta por... 1500 chiriguanos aliados y sólo 190 blancos (Martarelli, 1918 [1889]; 1892: 15). Baste con recordar, en fin, que si los blancos lograron apresar y ajusticiar al tumpa, fue porque uno de sus compañeros chiriguanos lo traicionó.

Esta visión del fracaso de Kuruyuki constituye un análisis más fino e históricamente más exacto, creo, que los que hablan de la «nación» chiriguana unida en su última lucha. En este aspecto, comparto la observación de Saignes, criticando

«[...] el empeño de los historiadores en presentar a la sublevación de 1892 como una coalición unitaria de casi todos las "capitanías regionales"». (Saignes,1990: 197)

5 Ava («hombre») es la autodenominación de muchos grupos guaraní-hablantes, incluidos los chiriguanos. 
Erick Langer se contenta con constatar, prudentemente, que los problemas internos fueron la causa del fracaso de Kuruyuki. Pero Saignes va más allá. Habla de «pasión suicida» (Saignes, 1985; 1990: 22), de una especie de acto voluntario en Kuruyukit: «Contra el Estado», los chiriguanos no pudieron más, y

«[...] han preferido eludir una violencia mayor surgida de la novedad política: el mando arbitrario y absoluto de sus propios líderes o de sus profetas». (Saignes, 1990: 241)

En Kuruyuki, «es el partido de la muerte que ganó» (Saignes, 1982); «al lanzarse a esta última rebelión, a esta matanza colectiva, debían sospechar su desenlace final». (Saignes, 1986: 205)

Mucho quedaría por decir sobre esta interpretación de Saignes, y en particular sobre la «novedad política» del «mando absoluto» de los líderes chiriguanos en 18926. En lo que a Kuruyukit toca, sin embargo, la conclusión sigue siendo la misma: los chiriguanos murieron «antes que esclavos vivir»; desaparecieron «en tanto que chiriguanos», en tanto que iyambae, para no ser esclavos hacia fuera (sometidos a los blancos) o hacia adentro (sometidos a un «Estado»).

Hasta aquí con la(s) visión(es) de los historiadores. Si queda mucho por discutir, algunos hechos deben, sin embargo, ser tomados en cuenta. Primero, simplemente... el hecho que los chiriguanos existen hoy, y que lo hacen saber en voz alta (aun si es bajo el nombre de «guaraní»). Si Kuruyukí fue «un fin», fue el fin de una época tal vez, el fin de cierta definición de la etnia, pero en ningún caso su fin físico ni — peor- su suicidio como lo sugirieron respectivamente Sanabria y Saignes. Segundo, los chiriguanos no solo existen hoy «físicamente», sino que siguen siendo una etnia «guerrera» o luchadora, líder del movimiento indígena en las tierras bajas bolivianas. Las armas de fuego callaron en Kuruyuki, pero fueron reemplazadas por papeles sellados, títulos de propiedad y demás «armas blancas». En zonas como el Isoso, incluso, se reivindica en voz muy alta la calidad de iyambae como apellido y esencia de la familia dirigente: evidentemente, Kuruyuki no fue, siquiera, el fin de «cierta definición» de la etnia.

\section{KURUYUKł, LA UNIÓN SAGRADA}

Sanabria Fernández escribió su Apiaguaiqui-Tumpa en 1972; la tesis de Thierry Saignes es de 1974, y el libro de Calzavarini de 1980. Poco después, en una Bolivia que estrenaba su nueva democracia, nació la Confederación Indígena de Bolivia (CIDOB), por iniciativa de —y con el apoyo de- una organización no gubernamental de desarrollo y de los antropólogos que trabajaban en ella. Cinco años más tarde, en 1987, se creó la Asamblea del Pueblo Guaraní (APG), organización política unificada de las diferentes capitanías chiriguanas. Como CIDOB, la APG nació por iniciativa de una institución de desarrollo, que contaba a varios antropólogos de renombre entre sus miembros.

La Asamblea que nace no es chiriguana: es guaraní. Jugó en esta denominación un rechazo evidente a las etimologías populares, y muy despreciativas, de la palabra «chiriguano»`. Jugó su papel también la historia misma de la conformación de la etnia, en la cual el elemento guaraní dominó siempre, en el plano político y de las representaciones, al elemento chané (Combès \& Saignes, 1991). «Guaranizados», los chiriguanos se proclaman hoy guaraní tout court, y escamotean «su herencia chané en beneficio exclusivo de sus raíces guaraní: acaso el último episodio en la historia de la "guaranización" de los chiriguanos» (Combès \& Villar, 2004); y, podríamos agregar, de la «guaranización» paralela de sus investigadores, quienes al estudiar

6 Sobre el papel de los capitanes chiriguanos no tan «clastreanos» como se sostuvo, ver Combès \& Lowrey (2004), Combès \& Villar (2004) y Combès (2004).

7 Desde los tiempos coloniales, «chiriguano» está interpretado, a partir del idioma quechua pero sin ninguna base lingüística, como «castigados por el frío»o, más comúnmente, como «excremento frío». 
hoy a los «guaraní» dejan demasiado fácilmente de lado el lado chané de la cultura chiriguana (Combès \& Lowrey, 2004). Pero esto es otra historia. Lo importante para nuestro propósito es que la APG sea también una «asamblea», la unificación política de un pueblo o de una «nación»: es una novedad absoluta, una ruptura histórica para con la tradición política chiriguana (Saignes, 1990: 52-53; Combès, 2004).

En este proceso intervinieron varios factores: un panorama político nacional e internacional favorable, el lema según el cual «la unión hace la fuerza» y — tal vez sobre todo- la visión de antropólogos y «asesores» de las capitanías, proyectando en la Asamblea y en los indígenas su propia imagen un tanto idealizada de la «nación guaraní». Así como algunos historiadores hicieron de Kuruyuki la lucha de un pueblo unido — para lamentar luego «el fin» de este pueblo—, hoy el mismo lema de la unión se proclama, pero para alentar la lucha indígena.

Flamante «nación» en busca todavía de definiciones propias, la APG quiere afirmar su «identidad» de pueblo. Lo hace, como no debe extrañarnos, buscando en su pasado raíces que la puedan sostener y legitimar hoy. En cualquier parte, en cualquier tiempo, notan Poutignat y Streiff-Fenart (1999: 131), la «identidad étnica» que se reivindica se refiere a un origen (a una historia) común, real o supuesta, entre los miembros del grupo. Pero Jean William subraya: «este pasado no es el de la ciencia histórica; es el que se representa la memoria colectiva» (in Poutignat \& Streiff-Fenart, 1999: 13); «la Historia, antes de ser una crítica y entonces una ciencia, es para los pueblos la idea que se forjan de su pasado» (Grenand, 1982: 33). Una idea, y no —o no siempre- una memoria. Hablando de los chiriguanos «como historiadores», Nordenskiöld notaba, en 1912:

«Cuando se habla con ellos, no saben mucho de su propia historia, y su tradición no remite a tiempos muy lejanos [...] Es realmente muy extraño que entre estas tribus indígenas hayan pasado al olvido asuntos como su historia, el nombre de los jefes etc. [...] los protagonistas de los cuentos y sus aventuras estimulan la fantasía, se retienen en la memoria y se cuentan a otros. Los personajes y acontecimientos históricos pasan al olvido». (Nordenskiöld, 2002 [1912]: 156-157)

Los padres franciscanos ya lo observaban:

«La historia de esta nación se pierde en el caos de los siglos. Como [el chiriguano] es renuente a esforzar un poco su entendimiento, recuerda sólo algo de las vicisitudes más próximas a él [...] los descendientes jamás conocen el nombre de sus ascendientes, oscuros o ilustres, que hayan existido en su tribu». (Giannecchini, 1996 [1898]: 357) la historia

«[...] está envuelta en el velo de la confusión, porque nunca nombran a sus finados, de donde resulta que los principales acontecimientos se ignoran, porque se desconocen los nombres de aquellos grandes que actuaron en ellos». (Nino, 1912: 67)

Métraux también escribe: «Los chiriguano no han conservado recuerdos de su historia pasada» (Métraux, 1931: 99), algo que también fue notado por los investigadores contemporáneos (Villar \& Bossert, 2004; Combès \& Villar, 2004). En 1988, varios entre los chiriguanos del Ingre y del Pilcomayo me hablaron del gran Kuimbae (Cumbay), quien fuera capitán grande de su zona a fines del siglo XVIII: conocían su nombre y sus hazañas... por haber leído un artículo de Thierry Saignes. En 1990, dos años apenas antes de la celebración del centenario de Kuruyukí, Albó notaba que nadie o casi nadie, entre los chiriguanos contemporáneos, se acordaba del tumpa de 1892 (Albó, 1990: 389).

De ahí la pregunta clave que plantea Saignes: «¿Cómo fundar una identidad colectiva sobre semejante olvido?» (Saignes, 1990: 200).

La respuesta me parece clara: para paliar el olvido, hay que reinventar la historia, recurriendo esta vez no a las fuentes históricas, sino al presente que se quiere forjar, y al futuro que se anhela. Thierry Saignes también escribía: 
Las batallas de Kuruyukt. Variaciones sobre una derrota chiriguana

«Si hay pérdida de la memoria histórica, es que no hay soporte social para darle sentido. El "olvido" de la tradición es voluntario». (Saignes, 1990: 219)

Creo que se puede invertir esta proposición: la reinvención de la historia es la que afirma y presta sentido a un nuevo soporte social. El hijo de un capitán del Isoso afirmaba a Silvia Hirsch:

«Saber la historia es una forma de política, ya que es una forma de defensa, de defender los intereses de la comunidad y de manejar a la gente». (Hirsch, 1991: 142)

A lo cual hace eco esta reflexión de Georges Duby:

«Siempre se han hecho chapuzas con la historia para consolidar un poder, para mantener una reivindicación. Quizá es para esto para lo que ha servido en primer lugar la historia. El pasado siempre ha sido triturado, atrapado en redes de discursos trenzados para rodear al adversario y para protegerse en las luchas en las que lo que está en juego es el poder [...] Siempre se manipula la historia, por supuesto, en función de intereses». (Duby, 1988: 75; subrayado de origen)

Y es así que el centenario de la batalla de Kuruyuki fue celebrado, en el lugar mismo de los hechos, «con bombos y platillos», discursos, y la presencia del mismo Presidente de la República boliviana. El acto fue auspiciado y organizado, sin sorpresa, por varias organizaciones e instituciones locales de desarrollo. Fue la celebración de la unión de un pueblo «jamás vencido», y la celebración de la «nación» chiriguana o guaraní. «Que Kuruyuki signifique hoy, pues, una ocasión más de solidaridad y de unidad», fue el tema de uno de los discursos de este día (Pifarré, 1992: 16).

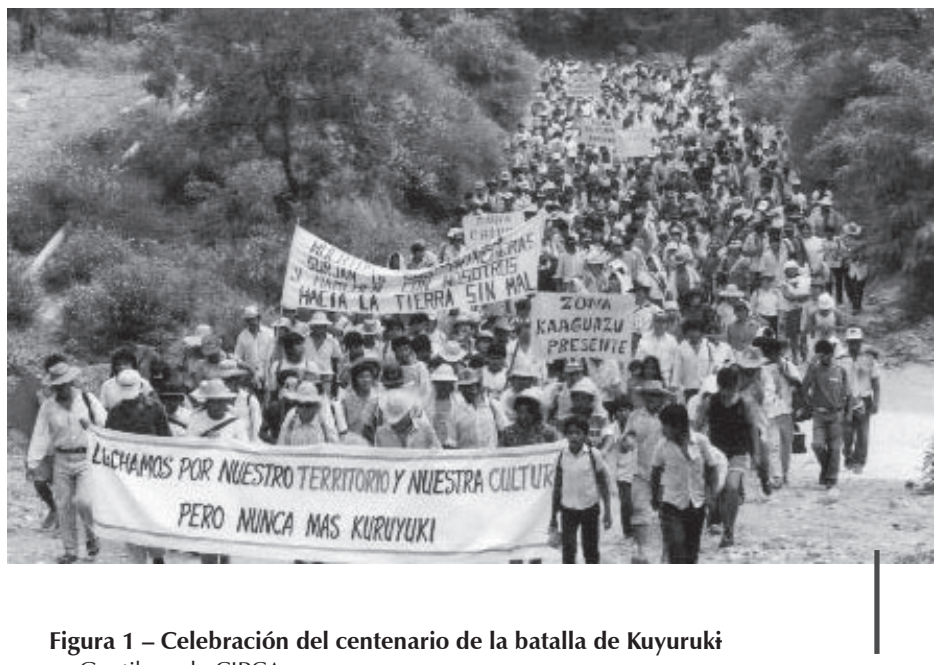
Gentileza de CIPCA

http:// www.cipca.org.bo/html/regional_cordillera/imagenes/cordillera_2.jpg Aparecieron letreros entre la multitud: «Muertos de Kuruyuki, surjan de sus trincheras, marchen con nosotros hacia la Tierra sin Mal» (Pifarré, 1992: 8): con toda evidencia, el Kuruyuki de las organizaciones indígenas de hoy (y de sus asesores) poco o nada tiene que ver con el de un Saignes o un Langer. Para dar un solo ejemplo, el Isoso, que participó al lado del ejército karai en contra del tumpa en 1892, no solo estuvo presente en 1992, sino que borró todo recuerdo en su historia oficial de su apoyo a los karai8. Más aún, una versión circuló que hacía de un karai del Isoso, muerto de un flechazo en la batalla... un asesor del mismísimo tumpa (Michel, 1985). Ya que el afán es hoy el de una «Asamblea» unida, entonces Kuruyuki debe ser la lucha de un pueblo unido. La conmemoración de 1992 «ratificó abiertamente a la APG como la organización matriz de los guaraní-chiriguanos» (Pifarré, 1992: 16).

8 Los capitanes del Isoso quisieron censurar a la autora de estas líneas cuando evocó la participación isoseña contra el tumpa en una publicación sobre la historia del Isoso; de la misma manera, decir que los isoseños son descendientes de chané, y ex esclavos de los ava chiriguanos, es un tema tabú. Tapïi en Isoso ya no quiere decir «esclavo», sino... «guaraní más puro». 
Así como los veredictos de los historiadores plantean problemas, la celebración de 1992 también provoca un cierto malestar. Del lado de los blancos (autoridades, instituciones, etc.) que participaron,

«[...] esta resurrección de un lejano antepasado algo fantasmático no está exenta de preocupaciones estratégicas: despertar de un sentimiento regionalista, defensa de recursos locales, promoción de la etnicidad». (Saignes, 1990: 200)

Basta con mencionar a los discursos actuales de los pseudo-historiadores del movimiento regionalista de Santa Cruz, la «Nación Camba». En febrero de 2004, uno de los principales ideólogos del movimiento, Carlos Dabdoub, escribió algunos párrafos sobre Kuruyukị en el foro-debate de la página web de la Nación Camba (www//.nacioncamba.net): en este escrito, hace de Kuruyuki una de las luchas federalistas cruceñas del siglo XIX; hace también de los chiriguanos - a menudo llamados «cambas» por los blancos, en un sentido muy despreciativolos antepasados de la actual «nación camba», es decir «cruceña». El mismo movimiento regionalista cuenta con sus «querembas» (keretmba: «guerrero» en guaraní) que son los que difunden sus tesis. Legitimación histórica otra vez de una «identidad», donde el gran ausente es, sin sorpresa, el «hecho histórico».

Del lado de los mismos chiriguanos, podemos retomar los argumentos de los historiadores: ¿Kuruyuki, unión contra el karai? Las fuentes históricas muestran hasta el cansancio que no. ¿La Asamblea del Pueblo Guaraní, unión de todo un pueblo? Hacia fuera sin duda, pero con muchos problemas adentro, que reproducen aquellas «rivalidades internas» tan analizadas por Saignes: por ejemplo la que opone a las capitanías chiriguanas (ava) de la región de Camiri, y la capitanía tapïi (chané, ex esclava) del Isoso, y que provocó, en 1993, el alejamiento del Isoso de la «Asamblea». Esto, sin hablar de aquellas extrañas referencias a la «Tierra sin Mal» que aparecieron en Kuruyuki y que debemos atribuir, una vez más, a las organizaciones y antropólogos que asesoran la APG y orquestaron la celebración. Este término fue evidentemente prestado de la literatura antropológica de Paraguay y Brasil: la «Tierra sin Mal» era hasta 1992 una expresión totalmente desconocida en la cordillera chiriguana10: es hoy uno de los principales puntos de referencia, uno de los «marcadores» esenciales de la «identidad chiriguana», o mejor dicho de la «identidad guaraní».

\section{PARA CONCLUIR}

¿Mentiras o verdades? Nada de eso sin duda, sino simplemente Historia. Después de 1987, los historiadores, sin poder ignorar a la APG, tuvieron que cambiar su discurso; estuvieron «obligados» a incorporar, en su diagnóstico, las palabras «despertar», incluso «resurrección». La presentación de los libros de Meliá, Pifarré y Albó publicados en 1988, 1989 y 1990, dice: «Este pueblo está despertando ya de la amnesia colectiva de la derrota»; en sus últimos escritos, Saignes emplea el mismo lenguaje y deja de lado su interpretación «suicida» de Kuruyuki (Saignes, 1989).

El discurso contemporáneo de la Asamblea del Pueblo Guaraní y el «recuerdo» de Kuruyuki son unas «mentiras» o unos «errores» históricos: nunca existió una unión política del «pueblo guaraní» y si tal unión existe hoy — lo que queda por demostrar- debe ser considerada, en todo caso, como una novedad. Pero esta mentira o equivocación del discurso es algo que llega a crear —o al menos, a consolidar — una realidad (¿una verdad?) actual, que es la organización

9 Agradezco a Ana María Lema por señalarme la existencia de este documento.

10 La imagen de una «tierra mejor» pudo existir y puede seguir existiendo entre los chiriguanos. A esta imagen pudo corresponder por ejemplo, el mito de Kandire en el siglo XVI y, en el siglo XIX, la Argentina llamada Mbaaporenda («tierra del trabajo»). Pero la palabra misma de «tierra sin mal», no ha sido recogida entre los chiriguanos, a quienes se atribuye con demasiada facilidad creencias de otros grupos guaraní mejor conocidos. 
de la Asamblea Guaraní. Con la APG, la «nación guaraní» nace como nación, sobre la base de un discurso histórico y étnico. En este caso entonces - y así como ocurre en el Baudolino de Umberto Eco- la «mentira» se vuelve verdad por su propia fuerza... y ya no es mentira. Lo mismo puede decirse del discurso de los historiadores: una «mentira» (el fin de los chiriguanos), que, sin embargo, se basa sobre «verdades» (las disensiones internas entre capitanías) que continúan siendo hoy verdaderas (y son los problemas actuales en el seno de la APG, entre ava y tapii en particular). Lo mismo, también, puede aplicarse al discurso de la Nación Camba, cuya presencia política en Santa Cruz — legitimada, entre otros mitos, por sus raíces «camba-guaraní» y Kuruyuki como lucha «federalista»— es una realidad con la cual se debe contar.

Kuruyuki es la más famosa de las batallas chiriguanas: porque fue la última, la mejor documentada (la única que tuvo los honores del periódico), y también porque tuvo su historiador exclusivo (Sanabria Fernández), bastante leído en Bolivia. Pero no fue la coalición más numerosa o importante de la historia chiriguana, no fue el «fin» que muchos vaticinaron, como no fue tampoco el sobresalto desesperado de todo un pueblo unido en contra del invasor y en busca de una utópica Tierra sin Mal... o de un federalismo cruceño.

La historia de Kuruyuki es, más que todo, la historia de sus historias y de sus avatares. A una revisión de Kuruyuki se dedicó Thierry Saignes en su último libro (Saignes, 1990: 187-198) a sabiendas, dijo él mismo, que «alguien más tarde hará lo mismo con [su] propio libro» (Saignes, 1990: 227): a una revisión de las revisiones quise contribuir con estas páginas. Los Kuruyuki son tan o más interesantes que el Kuruyuki y tal vez más importante aún, para el antropólogo y el historiador, que el «"hecho" que sucedió "realmente"», un 28 de enero de 1892, en las trincheras de la quebrada de Ivo.

\section{Referencias citadas}

Siglas de los archivos citados:

AFT Archivo Franciscano de Tarija

$\boldsymbol{H} \quad$ Historia

M Misiones entre infieles

ANB Archivo Nacional de Bolivia

EC Expedientes Coloniales

Rück Colección Rück

ALBÓ, X., 1990 - Los Guaraní-Chiriguano 3. La comunidad hoy, 433 p.; La Paz: CIPCA.

BLOCH, M., 2002 [1949] - Apologie pour l'histoire, ou Métier d'historien, 159 p.; París: Armand Colin.

CALZAVARINI, L., 1980 - Nación Chiriguana. Grandeza y ocaso, 320 p.; La Paz/Cochabamba: Los Amigos del Libro.

CHAVARRÍA, M., 1892 - Informe que presenta al Señor Ministro de Gobierno, el Delegado en las provincias de Tomina, Azero y Cordillera, Coronel Melchor Chavarría, 37 p.; Sucre: tipografía del Cruzado.

CLASTRES, H., 1975 - La Terre sans Mal. Le prophétisme tupi-guarani, 153 p.; París: Seuil. 
CLASTRES, P., 1974 - La société contre l'État: recherches d'anthropologie politique, 186 p.; París: Les éditions de Minuit.

CLASTRES, P., 1980 - Recherches en anthropologie politique, 248 p.; París: Seuil.

COMAJUNCOSA, A. \& CORRADO, A., 1884 - El Colegio franciscano de Tarija y sus misiones. Noticias históricas recogidas por dos misioneros del mismo Colegio, 567 p.; Quaracchi: tipografía del Colegio de San Buenaventura.

COMBÈS, I., 1991 - El testamento chiriguano: una política desconocida del post 1892. Bulletin de I'Institut Français d'Études Andines, 20 (1): 237-251.

COMBÈS, I., 2004 - ¿Con o sin dueños? Participación política y «democracia indígena» en el Chaco boliviano. T'inkazos, revista boliviana de ciencias sociales, 17: 119-128.

COMBÈS, I. \& LOWREY, K., 2004 - Slaves without masters? Arawakan dynasties among the Chiriguano (Bolivian Chaco, XVI-XX centuries). En prensa en Ethnohistory.

COMBÈS, I. \& SAIGNES, T., 1991 - Alter Ego. Naissance de l'identité chiriguano, 152 p.; París: EHESS. Cahiers de I'Homme.

COMBÈS, I. \& VILLAR, D., 2004 - Aristocracias chané. «Casas» en el Chaco argentino y boliviano. Journal de la Société des Américanistes, 90 (2): 63-102.

DUBY, G., 1988 - Diálogo sobre la Historia. Conversaciones con Guy Lardreau, 182 p.; Madrid: Alianza Universidad.

GIANNECCHINI, D., 1996 [1898] - Historia natural, etnografía, geografía, lingüística del Chaco boliviano, 459 p., Tarija: FIS-Centro Eclesial de Documentación.

GRENAND, P., 1982 - Ainsi parlaient nos ancêtres : essai d'ethnohistoire Wayampi, 390 p.; París : ORSTOM.

HIRSCH, S., 1991 - Political organization among the Izoceño indians of Bolivia, 293 p.; Los Angeles: PhD-thesis, UCLA.

LANGER, E., 1994 - Caciques y poder en las misiones franciscanas entre los chiriguanos en la crisis de 1892. Siglo XIX, 15: 82-103.

MARTARELLI, A., 1892 -Sublevación de los indios chiriguanos en las provincias de Azero y Cordillera, 23 p.; Potosí: El porvenir.

MARTARELLI, A., 1918 [1889] - El Colegio franciscano de Potosí y sus misiones. Noticias históricas, 314 p.; La Paz: sin editor. 2da edición corregida, aumentada y con notas por Bernardino de Nino.

MELIÀ, B., 1988 - Los Guaraní-Chiriguanos 1: Ñande Reko, nuestro modo de ser, 222 p.; La Paz: CIPCA.

MÉTRAUX, A., 1931 - Observaciones sobre la psicología de los indios chiriguano. Solar, 1: 89-122.

MÉTRAUX, A., 1967 - Religions et magies indiennes d'Amérique du Sud, 290 p.; París: Gallimard. MICHEL, F., 1985 - Kuaraya guasu. La sombra larga... la sombra grande, 3 p.; Camiri: mimeo.

MORENO, G.-R., 1973 - Catálogo del archivo de Mojos y Chiquitos, 583 p.; La Paz: lib. ed. Juventud. Notas de H. Sanabria Fernández.

NINO, B. de, 1912 - Etnografía chiriguana, 332 p.; La Paz: tipografía comercial I. Argote.

NINO, B. de, 1918 - Continuación de la historia de misiones franciscanas del Colegio de Propaganda Fide de Potosí, 269 p.; La Paz: ed. tipo-litográfico Marinoni.

NORDENSKIÖLD, E., 2002 [1912] - La vida de los indios. El Gran Chaco (Sudamérica), 312 p.; La Paz: APCOB-Plural.

PIFARRÉ, F., 1989 - Los Guaraní-Chiriguanos 2. Historia de un pueblo, 542 p.; La Paz: CIPCA.

PIFARRÉ, F., 1992 - Guaranís: el derecho a ser pueblo. Cuarto Intermedio, 23: 3-19.

POUTIGNAT, P. \& STREIFF-FENART, J., 1999 - Théories de l'ethnicité, suivi de «Les groupes ethniques et leurs frontières» de Fredrik Barth, 269 p.; París: PUF.

SAIGNES, T., 1974 - Une frontière fossile : la cordillère chiriguano au XVIIIo siècle, 436 p.; París: thèse de doctorat, EPHE. 
Las batallas de Kuruyukt. Variaciones sobre una derrota chiriguana

SAIGNES, T., 1982 - Guerres indiennes dans l'Amérique pionnière: le dilemme de la résistance chiriguano à la colonisation européenne (XVIo-XIXo siècles). Histoire, Économie, Société, 1: 77-103.

SAIGNES, T., 1985 - La Guerre contre I'Histoire. Les Chiriguano du XVIo au XIXo siècle. Journal de la Société des Américanistes, 71: 175-190.

SAIGNES, T., 1986 - Les sociétés des Andes Orientales face à l'État Républicain. In: Estados y Naciones en los Andes: hacia una historia comparativa, vol. 1 (Deler, J. P. \& Saint-Geours, Y., eds): 174-208; Lima: IFEA-IEP.

SAIGNES, T., 1989 - Reflexiones en torno a la cuestión chiriguana, 5 p., Camiri-Sucre: mimeo.

SAIGNES, T., 1990 - Ava y Karai. Ensayos sobre la historia chiriguano (siglos XVI-XX), 272 p., La Paz: HISBOL.

SANABRIA FERNÁNDEZ, H., 1972 - Apiaguaiqui-Tumpa. Biografía del pueblo chiriguano y de su último caudillo, 245 p., La Paz/Cochabamba: los Amigos del Libro.

SUSNIK, B., 1968 -Chiriguanos I. Dimensiones etnosociales, 269 p.; Asunción: Museo etnográfico Andrés Barbero.

VILLAR, D., \& BOSSERT F., 2004 - La onomástica chané en clave etnográfica y comparativa. Acta Americana, 12 (1): 49-78. 